\title{
Pemanfaatan Lumpur Minyak dengan Solar sebagai Energi Alternatif Bahan Bakar
}

\author{
[Utilization of Oil Sludge with Diesel as Fuel Alternative] \\ Yunus Tonapa Sarungu, Rony Pasonang Sihombing* \\ Department of Chemical Engineering, Politeknik Negeri Bandung
}

\begin{abstract}
Oil sludge resulting from crude oil processing in the petroleum industry could have a negative impact on the environment. Oil sludge could also be classified as hazardous waste and able to damage the environment and human health. Therefore, it was necessary to solve this issues. Oil sludge hydrocarbon utilizing to get higher value was one of solution offered by these research. In the utilization process, filtration method was used at first procedure and followed by diesel mixing at ratio $1: 0.1,1: 0.2,1: 0.3,1: 0.4$, and 1:0.5. The mixture was then analyzed for several parameters such as heating value, moisture content, ash content, and flashpoint. The results of heating values ranging from 5.966 calories/gram to 7.210 calories/gram, the flashpoint was from $38^{\circ} \mathrm{C}$ to $76^{\circ} \mathrm{C}$, the water content was from $51.89 \%$ to $54.52 \%$, the ash content was from $12.3 \%$ to $18.03 \%$. The results showed that utilization of oil sludge could be used as liquid fuel alternative energy.
\end{abstract}

\footnotetext{
Keywords: oil sludge, energy alternative, liquid fuel
}

Abstrak. Lumpur minyak hasil proses pengolahan minyak bumi dalam industri perminyakan dapat berdampak negatif terhadap lingkungan. Lumpur minyak juga dapat diklasifikasikan sebagai limbah B3 berbahaya dan dapat merusak lingkungan serta kesehatan manusia sehingga perlu dicari suatu teknologi untuk menangani kondisi tersebut. Pemanfaatan hidrokarbon dalam kandungan lumpur minyak agar memiliki nilai daya tambah merupakan salah satu solusi yang ditawarkan pada penelitian ini. Dalam proses pemanfaatannya, metode filtrasi digunakan pada tahapan awal dan dilanjutkan dengan pencampuran solar pada rasio 1:0,1;1:0,2;1:0,3;1:0,4;1:0,5. Produk campuran yang dihasilkan kemudian dilakukan analisis untuk beberapa parameter seperti nilai kalor, kadar air, kadar abu dan titik nyala. Hasil nilai kalor yang didapat mulai 5.966 kalori/ gram hingga 7.210 kalori/ gram, titik nyala yang didapat mulai dari $38^{\circ} \mathrm{C}$ hingga $76{ }^{\circ} \mathrm{C}$, kadar air yang didapat mulai $51,89 \%$ hingga $54,52 \%$, kadar abu yang didapat $12,3 \%$ hingga $18,03 \%$. Hasil penelitian menunjukkan bahwa pemanfaatan lumpur minyak dapat digunakan sebagai energi alternatif bahan bakar cair.

Kata kunci: lumpur minyak, energi alternatif, bahan bakar cair

Diterima: 2 Mei 2021, Disetujui: 12 Juli 2021

Sitasi: Sarungu, Y T., dan Sihombing, R P. (2021). Pemanfaatan Lumpur Minyak dengan Solar Sebagai Energi Alternatif Bahan Bakar. KOVALEN: Jurnal Riset Kimia, 7(2): 103-108.

\section{LATAR BELAKANG}

Lumpur minyak merupakan limbah yang masuk kategori limbah padat dan tidak dilakukan pengolahan lebih lanjut. Lumpur minyak (oil sludge) masih banyak mengandung

\footnotetext{
* Corresponding author

E-mail: rony.pasonang.sihombing@polban.ac.id
}

hidrokarbon sehingga dapat dimanfaatkan menjadi bahan bakar cair. Lumpur minyak berbentuk gumpalan - gumpalan padatan yang diselimuti cairan kental. Pada pemanasan dengan suhu $60^{\circ} \mathrm{C}$, bahan ini akan berubah menjadi cair namun pada suhu ruang akan berubah wujud menjadi padatan. Kandungan air masih terdapat di dalam lumpur minyak ini 
dan dapat dipisahkan dengan menggunakan pemanasan diatas suhu $60{ }^{\circ} \mathrm{C}$. Komponen dalam lumpur minyak antara lain adalah air (20 - 95\%), minyak (5 - 70\%), padatan (5 - 10\%) (Silalahi, 2015). Sebagai contoh, pada kilang di Cepu, dengan total 5.170 Liter/bulan (Sulistyono et al., 2011) akan dapat menghasilkan 62.037 Liter/tahun jika dikonversi menjadi satu tahun. Limbah lumpur minyak ini biasanya dapat ditemukan ketika loading dan unloading di storage tank. Selain itu dapat juga ditemukan pada saat pembersihan tangki pada proses di separator dan pompa feed maupun pompa produk.

Kandungan paling tinggi dalam limbah lumpur minyak yaitu hidrokarbon dan logam berat (Budihardjo, 2007; Prasetya et al., 2018). Lumpur minyak merupakan lumpur atau pasta hitam yang terkadang tercampur dengan air, tanah, kerikil dan bahan lainnya (Akhadiarto, 2010; Holifah, 2017). Lumpur tersebut akan menumpuk pada bagian dasar tangki penyimpanan dan berpotensi mengganggu proses berikutnya. Lumpur minyak terdiri dari minyak/ hidrokarbon, abu, air, pasir dan bahan kimia lainnya. Selain itu, di dalam hidrokarbon itu sendiri terdapat senyawa benzen, etilbenzen, xilena, toluena dan logam berat/ $\mathrm{Pb}$ (Silalahi, 2015). Contoh sampel dari lumpur minyak dapat dilihat pada Gambar 1.

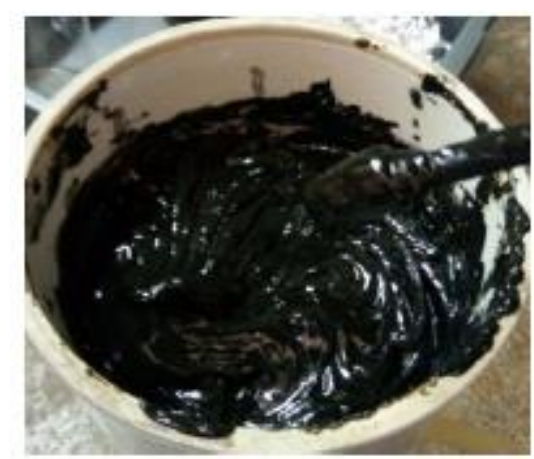

Gambar 1. Lumpur Minyak PT Pertamina Cepu.
Di dalam lumpur minyak terdapat kandungan logam berat. Hasil analisis logam berat pada lumpur minyak dari UP IV Cilacap dan UPPDN Balongan disajikan pada Tabel 1.

Tabel 1. Hasil analisis logam berat lumpur minyak (Suwarno, 2002)

\begin{tabular}{cccc}
\hline \multirow{2}{*}{ No } & Parameter & \multicolumn{2}{c}{ Kadar logam berat (ppm) } \\
\cline { 3 - 4 } & & $\begin{array}{c}\text { UP IV } \\
\text { Cilacap }\end{array}$ & $\begin{array}{c}\text { UPPDN } \\
\text { Balongan }\end{array}$ \\
\hline 1 & $\mathrm{As}$ & 17,935 & 7,084 \\
2 & $\mathrm{Hg}$ & 10,75 & 0,596 \\
3 & $\mathrm{Cu}$ & 7,949 & 1,14 \\
4 & $\mathrm{Zn}$ & 31,411 & 38,809 \\
5 & $\mathrm{Cr}$ & 1,538 & 0,656 \\
6 & $\mathrm{~Pb}$ & 0,281 & 0,226 \\
7 & $\mathrm{Cd}$ & 0,0079 & 0,035 \\
8 & $\mathrm{Ag}$ & 0,046 & 0,032 \\
\hline
\end{tabular}

\section{METODE PENELITIAN}

\section{Bahan dan Peralatan}

Bahan yang digunakan pada penelitian ini antara lain aquades, lumpur minyak yang diambil dari PT Pertamina Cepu, solar. Peralatan yang digunakan antara lain gelas kimia, pompa vakum, corong Buchner, kertas saring, spatula, filter bottle glass, hot plate, pipet tetes, neraca analitik dan corong pisah. Peralatan penguji yang digunakan antara lain calorimeter bomb, neraca analitik, furnace, desikator, oven dan flashpoint tester.

\section{Prosedur Penelitian}

Perlakuan awal yang dilakukan adalah pemanasan lumpur minyak hingga mencapai suhu $60-70^{\circ} \mathrm{C}$. Pertimbangan perlakuan ini adalah karena pada suhu tersebut lumpur minyak akan berwujud cair sehingga akan mempermudah melakukan tahap berikutnya, yaitu filtrasi vakum. Tujuan dilakukan proses filtrasi vakum adalam agar kandungan air yang terdapat pada lumpur minyak dapat dikurangi. 
Filtrat hasil dari proses vakum merupakan senyawa dengan kandungan komponen minyak dan air, sedangkan padatan yang dihasilkan akan masuk ke tahap selanjutnya yaitu tahap pencampuran.

Pada tahap pencampuran, dilakukan variasi perbandingan komposisi lumpur minyak dan air dengan rasio $1: 0,1 ; 1: 0,2 ; 1: 0,3 ; 1: 0,4$ dan 1: 0,5. Untuk mempercepat homogenisasi, dilakukan pencampuran dalam suhu $60-70^{\circ} \mathrm{C}$ menggunakan hotplate. Untuk penamaan sampel dapat dilihat pada tabel 2.

Tabel 2. Penomoran sampel

\begin{tabular}{ccc}
\hline No. & $\begin{array}{c}\text { Nomor } \\
\text { sampel }\end{array}$ & $\begin{array}{c}\text { Lumpur minyak: } \\
\text { solar }\end{array}$ \\
\hline 1 & 1 & $1: 0,1$ \\
2 & 2 & $1: 0,2$ \\
3 & 3 & $1: 0,3$ \\
4 & 4 & $1: 0,4$ \\
5 & 5 & $1: 0,5$ \\
\hline
\end{tabular}

Setelah pencampuran selesai, tahap berikutnya adalah tahap analisis produk. Beberapa pengujian yang dilakukan meliputi pengujian terkait kalor, titik nyala, kadar air dan kadar abu. Masing-masing pengujian dilakukan pengulangan sebanyak 3 kali untuk diketahui ketelitian/ standar deviasinya.

\section{Penentuan Kadar Abu}

Sebanyak 1 gram sampel diletakkan di dalam cawan kemudian dimasukkan ke dalam tanur dengan suhu $600^{\circ} \mathrm{C}$ selama 3 jam kemudian didinginkan di dalam desikator. Setelah dingin, sampel ditimbang (Asri \& Tjahjani, 2015).

\section{Penentuan Nilai Kalor dan Titik Nyala}

Nilai kalor dtentukan menggunakan alat bomb kalorimeter, sedangkan titik nyala dianalisis dengan alat rapied tester.

\section{Penentuan Kadar Air}

Penentuan kadar air menggunakan pemanasan dalam oven dengan temperature $103^{\circ} \mathrm{C}$ selama 30 menit. Hasil pemanasan kemudian didinginkan daam desikator lalu ditimbang dan dicatat datanya (Putra \& Murdiya, 2017). Kadar air ditentukan dengan persamaan

$$
\text { Kadar air }(\%)=\frac{\left(\mathrm{W}_{1}-\mathrm{W}_{2}\right)}{\left(\mathrm{W}_{1}-\mathrm{W}\right)} \times 100
$$

Dimana,

$$
\begin{aligned}
& \mathrm{W}=\text { Berat wadah kosong }(\mathrm{gr}) \\
& \mathrm{W}_{1}=\text { Berat wadah dengan sampel }(\mathrm{gr}) \\
& \mathrm{W}_{2} \text { = Berat sampel uji setelah pemanasan (gr) }
\end{aligned}
$$

\section{HASIL DAN PEMBAHASAN}

\section{Kondisi Awal Bahan Baku}

Analisis awal dilakukan untuk mengetahui kondisi bahan baku sebelum melakukan serangkaian pengujian. Tahap perlakuan awal bahan baku dimulai dengan proses filtrasi vakum dimana digunakan tekanan $(-0,3)$ bar hingga $(-0,4)$ bar. Waktu proses filtrasi yang digunakan adalah selama 3 jam dengan suhu $60-70{ }^{\circ} \mathrm{C}$ sebelum dimulai. Hasil analisis bahan baku dapat dilihat pada Tabel 3 .

Tabel 3. Hasil analisis bahan baku

\begin{tabular}{ccccc}
\hline No & Sampel & $\begin{array}{c}\text { Nilai kalor } \\
\text { (kalori/gram) }\end{array}$ & $\begin{array}{c}\text { Kadar } \\
\text { air } \\
(\%)\end{array}$ & $\begin{array}{c}\text { Kadar } \\
\text { abu } \\
(\%)\end{array}$ \\
\hline 1 & A & 4,349 & 61,03 & 16,87 \\
2 & B & 5,498 & 48,27 & 18,1 \\
\hline
\end{tabular}

Keterangan:

A: lumpur minyak sebelum filtrasi vakum

$B$ : lumpur minyak setelah filtrasi vakum

Dari tabel dapat dilihat bahwa ada penurunan kadar air. Hal ini berdampak pada meningkatnya kandungan padatan anorganik dalam lumpur minyak yang mengakibatkan nilai kalor dan nilai abu menjadi meningkat. Selanjutnya adalah analisa pada tahapan pencampuran dengan variasi komposisi lumpur minyak dan solar. 


\section{Pengaruh Rasio Lumpur Minyak : Solar pada Nilai Kalor}

Nilai kalor merupakan parameter pertama yang dilihat dari sebuah bahan bakar. Semakin besar nilai kalor suatu bahan bakar, semakin baik kualitas bahan bakar tersebut (Putri \& Sukandar, 2013). Pengaruh rasio lumpur minyak dan solar terhadap nilai kalor dapat dilihat pada Gambar 2.

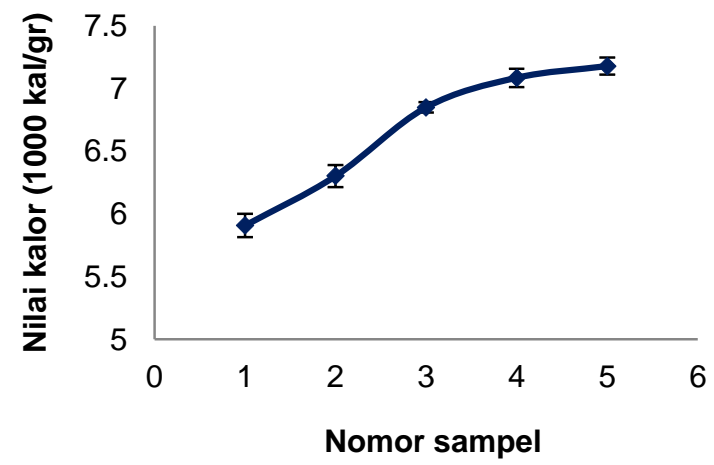

Gambar 2. Pengaruh rasio minyak: solar pada nilai kalor produk

Berdasarkan Gambar 2, penambahan komposisi solar terhadap lumpur minyak memberi pengaruh yang cukup nyata pada nilai kalor. Semakin kecil rasio minyak: solar maka semakin tinggi nilai kalor yang dihasilkan. Penyebab fenomena ini adalah lebih tingginya nilai kalor solar daripada lumpur minyak dimana nilainya sebesar 10.500 kalori/ gram. Disamping itu, sifat solar dan lumpur minyak dapat saling melarutkan, sehingga nilai kalor menjadi meningkat. Kandungan terbesar dari lumpur minyak adalah hidrokarbon, sehingga dengan meningkatnya jumlah hidrokarbon akan mampu meningkatkan nilai kalor sampel. Sebagai contoh perbandingan terhadap penelitian terdahulu terhadap arang kayu, dimana nilai kalor tertinggi terdapat di angka $6700 \mathrm{kal} / \mathrm{gr}$ (Hastuti et al., 2015). Sehingga rasio lumpur minyak dan solar dapat digunakan sebagai alternatif energi karena nilai kalor dapat mencapai hingga lebih dari $7000 \mathrm{kal} / \mathrm{gr}$.

\section{Pengaruh Rasio Lumpur Minyak : Solar pada Titik Nyala}

Titik nyala merupakan suhu saat terlihat nyala singkat pada suatu titik diatas permukaan bahan bakar (Pratama \& Yusuf, 2019). Biasanya nyala singkat yang dilakukan sekitar 1 hingga 4 detik. Pengaruh rasio lumpur minyak dan solar terhadap nilai titik nyala dapat dilihat pada Gambar 3.

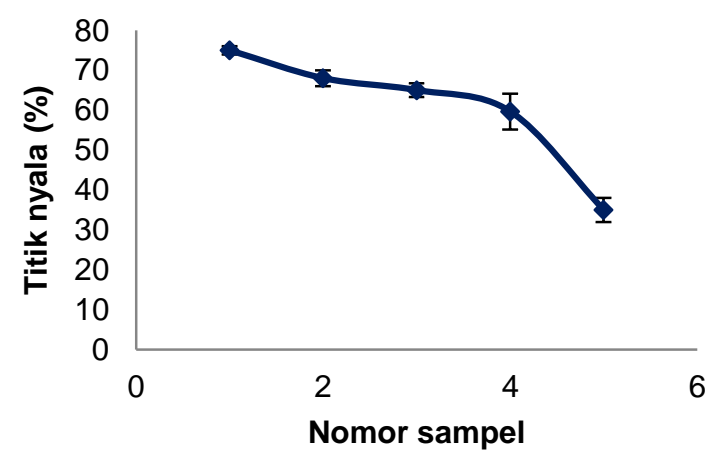

Gambar 3. Pengaruh rasio minyak: solar pada titik nyala produk

Terdapat penurunan nilai titik nyala dengan semakin bertambahnya jumlah rasio solar. Hal ini dikarenakan nilai titik nyala solar lebih rendah daripada lumpur minyak, yaitu 52 ${ }^{\circ} \mathrm{C}$ (Pertamina, 2015).

\section{Pengaruh Rasio Lumpur Minyak : Solar pada Kadar Air}

Kadar air merupakan jumlah/ komposisi air yang terdapat pada setiap gram bahan bakar. Besarnya kadar air suatu bahan bakar dapat menentukan kualitas dari bahan tersebut. Kadar air tinggi dapat menghambat proses penyalaan dikarenakan sifatnya yang noncombustible dan menurunkan suhu pembakaran suatu bahan. Pengaruh rasio lumpur minyak dan solar terhadap kadar air dapat dilihat pada Gambar 4.

Dapat dilihat bahwa terjadi penurunan kadar air pada Gambar 4. Fenomena ini terajadi karena adanya penurunan jumlah lumpur minyak dari sampel 1 hingga sampel 5 . 
Adanya penurunan jumlah lumpur minyak mengakibatkan terjadinya penurunan kadar air.

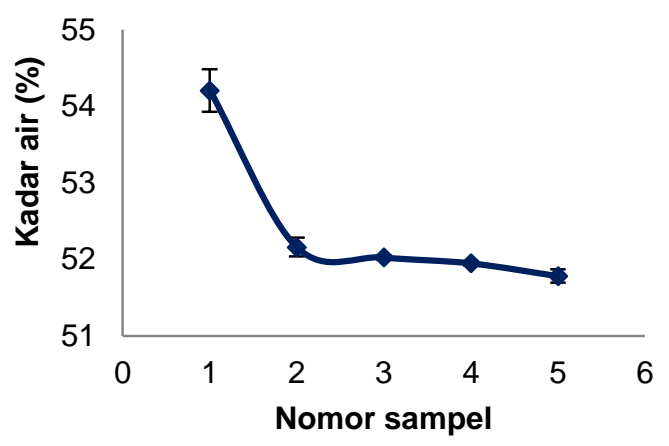

Gambar 4. Hasil analisa kadar air produk

\section{Pengaruh Rasio Lumpur Minyak : Solar pada Kadar Abu}

Kadar abu merupakan parameter penting untuk mengukur suatu komponen. Besarnya nilai kadar abu menunjukkan besarnya jumlah zat anorganik di dalamnya. Abu merupakan zat anorganik yang terdapat pada suatu bahan baku dan merupakan sisa hasil pembakaran sempurna (Kurniasari, 2018). Semakin tinggi kadar abu yang didapatkan menyebabkan semakin rendah kualitas suatu bahan bakar. Hasil analisis kadar abu dapat dilihat pada Gambar 5.

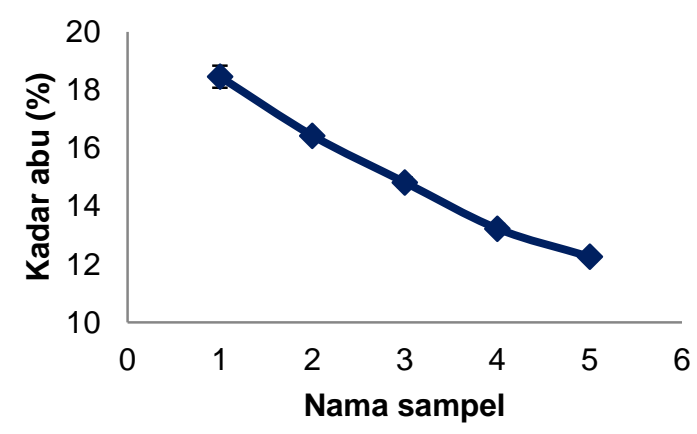

Gambar 5. Hasil analisa kadar abu produk

Besarnya nilai kadar abu menurun seiring menurunnya rasio minyak : solar. Hal ini disebabkan karena komposisi lumpur minyak di dalam produk semakin berkurang. Dengan berkurangnya jumlah lumpur minyak, padatan anorganik di dalam produk juga semakin berkurang.

\section{KESIMPULAN}

Pemanfaatan lumpur minyak dengan solar sebagai alternatif solusi bahan bakar cair telah selesai dilakukan. Berdasarkan hasil analisis nilai kalor, titik nyala, kadar air dan kadar abu, produk bahan bakar cair dapat dibuat dan dimanfaatkan sebagai solusi penggunaan energi alternatif.

\section{UCAPAN TERIMA KASIH}

Kami ucapkan terima kasih kepada Politeknik Negeri Bandung atas dukungannya. Penelitian ini dibiayai oleh Politeknik Negeri Bandung melalui Skema Penelitian Pemula dengan Surat Perjanjian nomor

B/73.3/PL1.R7/PG.00.03/2021

\section{DAFTAR PUSTAKA}

Akhadiarto, S. (2010). Peningkatan Nilai Nutrisi Limbah Lumpur Minyak Sawit Sebagai Pakan Ternak. JRL, 6(2): 175-186.

Asri, P., \& Tjahjani, S. (2015). Pemanfaatan Bungkil Biji Kapuk (Ceiba Pentandra) Sebagai Campuranbriket Sekam Padithe Utilization Of Cotton Seed Meal (Ceiba pentandra) as a Mixture Ofa Rice Husk Briquette. UNESA Journal of Chemistry, 4(1): 63-64.

Budihardjo, M. A. (2007). Studi Pengaruh Bulking Agents Pada Proses Bioremediasi Lumpur Minyak. Jurnal Purifikasi, 8(1): 55-60.

Hastuti, N., Pari, G., \& Setiawan, D. (2015). Kualitas Arang 6 Jenis Kayu Asal Jawa Barat Sebagai Produk. Jurnal Penelitian Hasil Hutan, 33, 337-346.

Holifah, S. (2017). Analisis Penambahan Kotoran Kambing Dan Kuda Pada Proses Bioremediasi Oil Sludgedi Pertambangan Desa Wonocolo. [Skripsi]. Universitas Negeri Semarang, Semarang.

Kurniasari, H. D. (2018). Pemanfaatan sludge 
limbah biodigester untuk meningkatkan

kecepatan produksi biogas dan konsentrasi gas metan dalam biogas. Offshore, 2(2): 43-54.

Pertamina. (2015). Spesifikasi Solar/ Biosolar. $1,17$.

Prasetya, B., Sudijono, S., \& Kasinoputro, P. (2018). Pemanfaatan Lumpur Minyak untuk Pembuatan Komposit Berserat Lignoselulosa Utilization of Oil Sludge as a Lignocellulosic Fiber Reinforced Composite Material. Jurnal IImu Dan Teknologi Kayu Tropis, 4(1): 9-14.

Pratama, GNIP., \& Yusuf, A M. (2019). Uji Titik Nyala Dan Titik Bakar Semarbut Aspal Tipe 4 Berdasarkan Sni 2433:2011. INERSIA: Informasi Dan Ekspose Hasil Riset Teknik Slpil Dan Arsitektur, 15(1): 62-73.

https://doi.org/10.21831/inersia.v15i1.248 64

Putra, R. K., \& Murdiya, F. (2017). Karakteristik Tegangan Tembus Arus Bolak Balik Pada Minyak Jarak Pagar (Jatropha curcas) Sebagai Alternatif Isolasi Cair. Jom FTEKNIK, 4(2): 1-11.

Putri, A. P., \& Sukandar, S. (2013). Studi Pemanfaatan Limbah B3 Sludge Produced Water Sebagai Bahan Baku Refuse Derived Fuel (Rdf). Jurnal Tehnik Lingkungan, $19(1)$ : 1-10. https://doi.org/10.5614/jtl.2013.19.1.1

Silalahi, M. (2015). Pengolahan Limbah Lumpur Minyak (Oil Sludge) Menjadi Bahan Bakar Gas Alternatif. Project Report. FALTL - USAKTI, Jakarta.

Sulistyono, S., Suntoro, S., \& Masykuri, M. (2011). Kajian dampak tumpahan minyak dari kegiatan operasi kilang minyak terhadap kualitas air dan tanah (Studi Kasus Kilang Minyak Pusdiklat Migas Cepu). Jurnal Ekosains, 4(2): 23-34. http://jurnal.pasca.uns.ac.id/index.php/ek osains/article/view/267/252

Suwarno. (2002). Pemanfaatan Padatan Sludge Minyak Sebagai Bahan Pencampur Pembuatan Bata Merah. [Tesis]. Program Pasca Sarjana Universitas Diponegoro, Semarang. 